\title{
PRINCÍPIO DA AFETIVIDADE NO DIREITO DE FAMÍLIA BRASILEIRO: JUSTIÇA E EXCLUSÃO DA FAMÍLIA HOMOAFETIVA
}

\author{
PRINCIPLE OF THE RIGHT AFFECTIVITY BRAZILIAN FAMILY JUSTICE \\ AND FAMILY EXCLUSION SEXUAL DIVERSITY
}

\author{
${ }^{1}$ Marina Ribeiro Guimarães Mendonça \\ ${ }^{2}$ Lucas De Souza Lehfeld
}

\section{RESUMO}

Justiça e Exclusão. Nada mais imperativo que esses dois ingredientes somados a diversidade sexual. A mesma sociedade que avança ideologicamente e pleiteia a tutela dos direitos homoafetivos é a mesma que os exclui com agravado preconceito e agressão aos Direitos Fundamentais. Mesmo com nítido avanço do Poder Judiciário quanto a extensão do conceito de família, sob o prisma do valor jurídico ao afeto como demonstração de "justiça", é crescente a "exclusão" dos homossexuais em decorrência das dificuldades que se seguiram quanto à equiparação de direitos e deveres dos efeitos jurídicos da união homoafetiva em meio ao preconceito social predominante.

Palavras-chave: Novas famílias brasileiras, Princípio da afetividade, Homoafetividade

\begin{abstract}
Justice and Exclusion. Nothing more imperative that these two ingredients added sexual diversity. The society that advances ideologically and plead the protection of sexual diversity rights is the same as the rule with aggravated assault and prejudice to fundamental rights. Even with clear improvement of the judiciary as the extension of the concept of family, in the light of the legal value to affection as a demonstration of "justice", it is increasing the "exclusion" homosexuals as a result of the difficulties that followed as the equal rights and duties of the legal effects sexual diversity marriage the prevailing social prejudice.
\end{abstract}

Keywords: New brazilian families, Principle of affection, Sexual divesity

\footnotetext{
${ }^{1}$ Mestre em Direitos Coletivos e Cidadania pela Universidade de Ribeirão Preto-UNAERP, Sao Paulo, (Brasil) Email: tutortreinamneto@gmail.com

${ }^{2}$ Pós-Doutor em Direito pela Universidade de Coimbra, Portugal Professor titular da Universidade de Ribeirão Preto, São Paulo, (Brasil).
} 


\section{INTRODUÇÃO}

Afeto e preconceito. Reconhecimento da União Estável Homoafetiva e falta de legislação. Justiça e Exclusão. Esse cenário de contrariedade vem se destacando no Direito de Família Brasileiro e no dever do Estado, e de todos os cidadãos, em promover a igualdade e oportunidade de direitos, assegurando a Dignidade Humana, aos membros da nação independente de sua opção afetiva.

Ao envolver união de pessoas do mesmo sexo e seus consequentes efeitos jurídicos, a proteção juspolítica ainda ocasiona insegurança, mesmo com inúmeros avanços doutrinários, jurídicos e de politicas públicas de comprovada eficácia social, resultando, em 2011, no reconhecimento pelo STF do precedente da equiparação da união estável aos relacionamentos homossexuais.

No entanto, a negativa de legislação, sobre as consequências jurídicas de uniões homoafetivas, permitiu crescentes discordâncias jurídicas somadas às dificuldades em regulamentar os direitos e deveres sociais decorrentes dessa união ameaçando garantias e direitos fundamentais do indivíduo, mesmo sob a nítida evolução do Poder Judiciário em busca de "justiça".

No mesmo sentido, a mobilização social a cerca do tema tem reações opostas e abre lacunas para crescentes relatos de violência contra homossexuais relativizadas pelo preconceito. Muitos ativistas atribuem à marginalização legal essa negativa social pautada na "exclusão" dos iguais concretizando a Homofobia que fere a Dignidade Humana no tocante, além das garantias mínimas inerentes ao ser humano, à igualdade constitucional.

\section{METODOLOGIA}

Sob essa perspectiva, o trabalho procura demonstrar a evolução dos tipos de família e entidades familiares, através de pesquisa qualitativa teórica, a partir do objetivo do Direito de Família, que é a tutela da família em sentido amplo, e a natureza protetiva inerente aos grupos domésticos em todos os aspectos, atrelados aos novos fenômenos sociais, como forma de acompanhar a transgressão e evolução da sociedade aquém do conceito de família ligada apenas ao matrimônio e a ideologia religiosa, impondo ao Estado o reconhecimento e proteção de direitos e deveres oriundos dos relacionamentos extramatrimoniais e os efeitos jurídicos da união estável. 
Agrega-se, portanto, nas decisões judiciais e evolução legal o valor jurídico ao afeto, como vem desempenhando esse importante instituto do Direito Brasileiro, que singularmente, pauta-se em princípios, fontes, normas, técnicas distintas de outros ramos do Direito público e privado, e muitas vezes negado pelo próprio Direito Civil, em busca de assegurar a matriz afetiva nas relações familiares.

O importante cenário das discussões sobre as novas famílias, seus direitos e consequências jurídicas das relações interpessoais, interfere diretamente nas uniões homoafetivas por ser a diversidade sexual, ainda, um requisito essencial na configuração da união estável. Para tanto, o trabalho parte seu estudo das premissas jusfundamentais do Direito de Família, ou seja, o casamento, a união estável, as relações de parentesco e os institutos do direito protetivo a fim de demostrar a importância da afetividade sob o olhar panorâmico dos conceitos das novas famílias e entidades familiares e a inclusão no mundo jurídico da união homoafetiva.

A intenção é comparar os avanços sociais e jurídicos sobre as novas relações familiares entre homens e mulheres e o reconhecimento pelo ordenamento jurídico brasileiro da união estável, com as consequências jurídicas da equiparação da união homoafetiva, fortalecendo a analogia jurídica e o bem-estar social.

Ilustra-se um paralelo com os direitos assegurados às famílias e entidades"extramatrimoniais"sob a premissa de comprovar os novos paradigmas do Direito de Família brasileiro através da inclusão e alargamento conceitual dos atuais tipos de familia e entidades familiarese as mais recentes decisões judiciais sobre $o$ reconhecimento dos argumentos jurídicos que baseiam a decisão do STF de 2011, sobre família homoafetiva. Ambos inerentes do princípio da afetividade,como sinônimo de "justiça".

Parte desse pressuposto, de avanço e justiça, para avaliar a"exclusão" das uniões homafetivas no contexto de nova família brasileira, respaldada nas dificuldades encontradas pelos casais homoafetivos em assegurar os direitosa eles garantidos e equiparados descrevendo uma situação longe de ser pacifica. Passa-se, então, a estruturar os aspectos sociais referentes à marginalização legal dos Direitos Homoafetivos, discrepantes decisões judiciais ao longo do tempo e a crescente violência ligada ao preconceito. Ou seja, a Família Homoafetiva, ainda evidencia um cenário de "justiça" e "exclusão" ao bem jurídico de maior proteção constitucional, o ser humano! 


\section{DESENVOLVIMENTO}

\section{A EVOLUÇÃO JURÍDICA E SOCIAL DAS NOVAS FAMÍLIAS SOB A LUZ DO PRINCÍPIO DA AFETIVIDADE: “JUSTIÇA!”}

Com a intenção de contextualizar a realidade brasileira sobre os avanços no Direito de Família resultando em novos paradigmas, o trabalho inicia sua abordagem, através do objetivo, natureza jurídica e princípios que norteiam as novas familias brasileiras. Para tanto, demostra que a afetividade é o principal ingrediente nessa luta social para o reconhecimento constitucional de novas famílias, atribuindo-lhe direitos e deveres a partir do reconhecimento do ordenamento jurídico da união estável. Nesse sentido, demostra que a mesma afetividade foi capaz de transgredir lacunas legislativas, moral e religiosa, que ainda implicam e ameaçam a igualdade e dignidade humana, ao equiparar a união homoafetiva, em precedente do STF, ocasionando um ato de "justiça" social e jurídica.

\subsection{O MODERNO DIREITO DE FAMÍLIA}

O casamento era assim obrigatório. Não tinha por fim o prazer; o seu objeto principal não estava na união de dois seres mutuamente simpatizantes um com o outro e querendo associar-se para a felicidade e para as canseiras da vida. $\mathrm{O}$ efeito do casamento, à face da religião e das leis, estaria na união de dois seres no mesmo culto doméstico, fazendo deles nascer um terceiro, apto para continuador desse culto (COULANGES, 1958, p.45).

Sob essa perspectiva, do principal objetivo do casamento, partem as premissas do trabalho na tentativa de compreender a evolução jurídica e social da entidade Família até a construção dos novos paradigmas atribuídos ao Direito de Família e as novas entidades familiares. Família, em sentido amplo, é a base que sustenta esse ordenamento jurídico do Direito Civil moderno. De difícil definição, pois, o próprio código de Direito Civil não define o que vem a ser família e, ademais, foge de um consenso entre Direito, Sociologia e Antropologia. Sofre de inúmeros alargamentos conceituais no intuito de proteger, entre outros, a família brasileira, o patrimônio, a instituição casamento, e por fim, a união estável em conformidade com as mudanças sociais. 
A fim de evitar maiores divergências, o Direito Civil moderno atribui ao conceito de família as pessoas unidas por relação conjugal ou de parentesco permitindo que as legislações infraconstitucionais definam os membros da unidade de parentesco.O Direito de Família, portanto, estuda as relações familiares pautadas pelas uniões, tanto as matrimoniais quanto as extramatrimoniais, e tudo que delas resultam assistencialmente e patrimonialmente, por maisque, na esfera atual, o aspecto do patrimônio seja considerado secundário pelo Direito por estaremàs relações familiares fincadas na ética e moral afetivas.

Para se compreender a realidade moderna do Direito de Familia, necessário se faz a alusão ao passado sobre o casamento e a evolução social e jurídica desse organismo. Pois, ocasamento é, ainda, considerado o "centro gravitador" do Direito de Família (VENOSA, 2014).'Indubitavelmente, o centro de onde irradiam as normas básicas do Direito de Família, que constituem o Direito Matrimonial (DINIZ, 2015. p.48)".

A base histórica desse organismo social é muito forte e seus resquícios se introduzem diretamente no Direito, ao condicionar família ao casamento como há muito se pautou o ordenamento jurídico brasileiro, regulamentado, ademais, pelo Estado, o que afastava qualquer conotação afetiva da união.Nesse sentido, Bevilaqua defende a instituição casamento afastando da definição doutrinária a família, como reproduziu em 1937 (BEVILACQUA, 1937, p.6).

Direito de família é o complexo das normas, que regulam a celebração do casamento, sua validade e os efeitos, que dele resultam, as relações pessoais e econômicas a sociedade conjugal, a dissolução desta, as relações entre pais e filhos, o vinculo de parentesco e os institutos complementares de tutela e curatela.

A contextualização histórica do casamento sobrepondo-se a figura da família, que preexistente a estruturação jurídica,pode ser percebida já no Código Civil de 1916 ao ignorar as relações familiares fora do matrimônio. No entanto, as transgressões sociais, aparentes a partir da Segunda Guerra Mundial e seu capitalismo expansionista, resultaram em uma sociedade desgastada pelo trabalho intenso e economia pessoal desfavorável, desencadeando uma onda de divórcios e casamentos fora do matrimonio 
as quais tiveram forte influência na aceitação social e jurídica das relações familiares extramatrimoniais.

"A unidade familiar, sob o prisma social e jurídico, não mais tem como baluarte exclusivo o matrimonio. A nova família estrutura-se independente das núpcias. Coube à ciência jurídica acompanhar legislativamente essas transformações sociais (VENOSA, 2014, p.6)" e estruturar direitos e deveres daquelas Novas Familias brasileiras para garantir os Direitos Fundamentais e o bem-estar social. Ruggiero (1972) citado por Diniz (2015, p.48) pondera que "todo direito de familia repousam nessa ideia: os vínculos se estabelecem e os poderes se outorgam nem tanto para criar direitos, como para impor deveres".

Nesse contexto, inicia-se a confecção do Direito Civil moderno e as premissas do Direito de Família pautados na família digna de afeto. A Constituição Federal de 1988, os inúmeros decretos, súmulas e jurisprudências que se seguiram, permitiram, contudo, o nítido avanço social e jurídico ao voltar os olhosjusfundamentais do Direito de Família para a família em conceito alargado.

Assim, com a evolução social e jurídica, das últimas décadas é que se apresenta a familia em sentido amplo e o artigo 226, paragrafo $4^{\circ}$ da Magna Carta menciona de forma clara e objetiva a tendência de inclusão das pessoas unidas por vínculo jurídico de natureza familiar (DINIZ, 2015, p.50). Faz saber: "entende-se, também como entidade familiar a comunidade formada por qualquer dos pais e seus descendentes".

Nesse particular, a Lei Máxima brasileira ao garantir as entidades familiares mostra o quanto à extensão de família se movimentou no curso dos tempos.Demonstra, para tanto, que o Direito de Família possui características peculiares de ordem pública predominantee que hoje possui proteção do Estado à sociedade conjugal com ou sem casamento, todas envolvidas na busca e proteção ao bem-estar social e principalmente $o$ afeto.

Seu objetivo, portanto, é assegurar a própria família em seus inúmeros sentidos. Contudo, pertinente é a delimitação dessa palavra para que a plurivalência semântica não incorra em ameaça jurídica (PEREIRA, 2014). Destacam-se três vocábulos fundamentais de família: a amplíssima (vínculo consanguíneo ou afinidade, formada, por exemplo, por parentes próximos); a lata (além dos cônjuges e filhos abrange os parentes em linha reta ou colateral); a restrita (unidos pelos laços de matrimonio e de filiação) (DINIZ, 2015). 
O que permite compreender nas classificações é que familia, hoje, vai além de matrimonio, tornando o convívio mais forte e fincando suas bases no amor eafeto. Vislumbra-se um moderno Direito de Familia constituído por direitos e deveres próprios. Nesse sentido, busca-se proteger, além do direito matrimonial, o direito convivencial, o direito parental e o direito assistencial resultantes do amplo conceito de família moderna (DINIZ, 2015), pois, a família é um fenômeno fundado em dados biológicos, sociológicos e psicológicos que devem ser reguladas pelo Direito.

Nessa seara atual e evoluída, de inversão de valores, conquista de direitos das mulheres, liberação sexual, desbiologização dos pais entre tantas outras rápidas alterações, influenciaram e influenciam diretamente no Direito de Família. Esses novos temas estão a desafiar o legislador que tem como principal função acolher as mudanças a fim de preservar os valores culturais na coesão da família em sentido amplo, de conceituação extensa, para que seja protegida juridicamente também a entidade familiar.

Porém, quais são seus direitos e deveres? Equipara-se ao casamento? Constróise um novo fundamento jurídico? E a sucessão?A conjuntura atual busca no Direito de Familia a solução para os empasses não ditos no texto das legislações brasileiras. E o moderno Direito de Familia procura a proteção devida para não infringir os direitos fundamentais e a dignidade humana nos seus distintos princípios.

Cita-se, para tanto, osprincípios: da "ratio" do matrimonio; da Igualdade jurídica e dos cônjuges e dos companheiros; igualdade jurídica de todos os filhos; pluralismo familiar; Consagração do poder familiar; liberdade; Do respeito da Dignidade da Pessoa Humana; Superior interesse da criança e do adolescente; Afetividade. O trabalho aprofunda-se no principio da afetividade como base da Dignidade da Pessoa Humana. No entanto, as bases axiológicas do Direito de Família moderno estão estruturadas nesses princípios extremamente importantes para a construção do bem-estar social no contexto de entidades familiares.

Maria Helena Diniz aborda tais princípios, resumidamente, dispostosa seguir. A partir de seu pensamento é possível compreender o quanto a afetividade é importante na construção dos novos paradigmas do Direito de Família (DINIZ, 2015, p.420).

Princípio da "ratio" do matrimonio: Segundo este princípio o fundamento básico do casamento e da vida conjugal e a afeição entre os cônjuges e a necessidade de que completa comunhão de vida; Principio da Igualdadejurídica e dos cônjuges e dos companheiros:com esse principio desaparece o poder marital, e a autocraia do chefe de família é substituída por um sistema em que as decisões devem ser 
tomada de comum acordo entre marido e mulher ou convenientes, pois os tempos atuais requerem que a mulher seja colaboradora do homem e não sua subordinada e que haja paridade de direitos e deveres entre cônjuges e companheiros; Principio da igualdadejurídica de todos os filhos: com base nesse principio não se faz distinção entre filhos matrimoniais, não matrimoniais ou adotivos quanto ao poder familiar, nome e sucessão; permite-se o reconhecimento de filhos extramatrimoniais e proíbe-se que se revele no assento do nascimento à ilegitimidade simples ou espuriedade; Principio do pluralismo familiar: reconhecimento da família matrimonial e da entidade familiar;Principio da Consagração do poder familiar: o poder-dever de dirigir a família é exercido conjuntamente por ambos os genitores desaparecendo o poder marital e paterno;Principio da liberdade: destina-se ao livre poder de formar uma comunhão de vida, livre decisão do casal no planejamento familiar, livre escolha do regime matrimonial de bens, livre aquisição do patrimonio familiar, livre opção pelo modelo de formação educacional, cultutal e religiosa da prole;Principio do respeito da Dignidade da Pessoa Humana: garantia do pleno desenvolvimento dos membros da comunidade familiar; Principio Superior interesse da criança e do adolescente: garantia de desenvolvimento pleno dos direitos da personalidade do menor $\mathrm{e}$ diretriz solucionadora de questões conflitivas oriundas da separação judicial ou divorcio dos genitores;Principio Afetividade: base do respeito a dignidade, norteadora das relações familiares e da solidariedade familiar.

Seguindo a evolução jurídica e social, coube a Constituição amparar algumas entidadesfamiliares, assegurado, ademais, pelo princípio da pluralidade familiar. No entanto, não esgotou ou limitou os tipos de família. Em destaque, seguem algumas famílias reconhecidas pela Magna Carta para então compreender a família homoafetiva e seus principais aspectos jurídicos.

São elas: Família Matrimonial decorrente do casamento, Família informal, amparada pela união estável Família monoparentalque é composta por pai ou mãe e seus filhos (BRASIL, 1988). Ainda, permite reconhecer a Familia anaparental, considerada comofamília sem pai e mãe, por exemplos,dois irmãos; avós e seus netos, e aFamilia mosaico (reconstituídas ou recompostas) traduzida pela atual circunstância da sociedade composta por pessoas que tiveram casamento ou união estável anterior e iniciam nova união estável ou casamento, com ou sem filhos.

Para efetivar os direitos e deveres da família em sentido amplo, como garantido pela Constituição Federal, o STJ na Súmula de número 364 pressupõe que família depende da existência do outro. Portanto, a pessoa que não tiver ascendentes, cônjuge ou companheiro ou colaterais não é família. Em se tratando de proteção do bem de 
família de pessoa solteira recorre apenas à garantia de um mínimo existencial, que concretiza a dignidade da pessoa humana.

Sob essa perspectiva, o trabalho busca elucidar o reconhecimento da união estável,pautada na afetividade, como resultado da evolução jurídica e social positivadas pela Constituição Federal ao reconhecer asmodernas entidades familiares. Abordando- se, no mesmo sentido a família homoafetiva reconhecida em precedente do Supremo Tribunal Federal (STF), ao compreender que a Constituição Federal possui um rol exemplificativo em se tratando de família, como expoente maior de "justiça" pretendida por esse peculiar ramo do Direito Civil: o moderno Direito de Família.

\subsubsection{A UNIÃO ESTÁVEL, A UNIÃO HOMOAFETIVA E O VALOR JURÍDICO AO AFETO}

O trabalho concentra-se na união estável como resultado aclamado de uma evolução jurídica e social sobre as famílias brasileiras. Devido à falta de contornos legais do tema, mesmo respaldado pela Magna Carta, desafia os juristas na conjuntura atual da sociedade. Por mais que a Constituição Federal tenha o condão de reconhecer a realidade social, e, portanto, não pode desconhecer a união estável, realmente não a fez, não a excluiu. Permitiu, para tanto que a conversão da união estável em casamento seja realizada de forma simples, não solene e formal. Então, não a equiparou ao casamento. Seu condicionamento foi realizado para fins de proteção do Estado como entidade familiar observado todo o esforço para diferenciá-la do concubinato.

Maria helena Diniz garante que o reconhecimento da União Estável "não deve gerar consequências idênticas ao do matrimonio (DINIZ, 2015, p.446)". A união estável, portanto, desintegra-se das sociedades de fato transgredindo seu status ao mundo das entidades familiares atribuindo elementos para sua conceituação. Entre eles, destaca-se a ausência de matrimonio e impedimentos matrimoniais, relação duradoura, fidelidade e lealdade, notoriedade de afeições recíprocase em destaque a diversidade de sexo. Esses elementos permitem direitos e deveres antes negados para as famílias extramatrimoniais.

No entanto, a doutrinadora parte do novo Código Civil, a legislação extravagante e a jurisprudências para atribuir a evolução "no sentido de possibilitar que, além dos deveres de lealdade, respeito, assistência mutua material e imaterial, haja responsabilidade pela guarda, pelo sustento e pela educação dos filhos na proporção dos haveres e 
rendimentos dos conviventes (CC, art. 1724) (DINIZ, 2015, p.447)" e produza alguns efeitos jurídicos, a título de exemplificação, permitir que a convivente tenha o direito de usar o nome do companheiro (lei 6015/73, artigo 57 e parágrafos, que entrou em vigor em $1^{\circ}$ de janeiro de 1976 com alteração da lei 6.216/75).

Outros direitos alcançados, dentre os inúmeros, referem-se a acidente de trabalho tal como a esposa; "Construir bem de familia (C.C, artigo 1711) e o vinculo de parentesco por afinidade entre conviventes e os parentes do doutro (C.C1595) sendo que, na linha reta, tal vínculo não se distinguirá com a dissolução da união estável gerando impedimento matrimonial". Direitos antes negados e atualmente assegurados pelo reconhecimento da união estável ${ }^{1}$.

Conclui-se que as entidades familiares ainda buscam seus direitos e deveres no judiciário devido à falta de legislação. Porém, a Constituição, ao transgredir a realidade extramatrimonial para as garantias constitucionais, facilita as decisões judiciais para equiparação de direitos e deveres. Assim, “a preocupação do interprete será sempre aplicar a norma de forma mais adequada, no aqui e agora. Toda decisão será injusta se utilizar fundamentos do passado ou tentar prever o futuro (VENOSA, 2014, p.442)", assegurando, portanto, a família em sentido amplo.

Contudo, um dos requisitos para a concessão de união estável está pautado na diversidade sexual. O que realmente demostra um cenário de "justiça", a partir da evolução, no Direito de Família, pois, não há nem mesmo alusão constitucional direta as famílias homoafetivas. Como adverte João Baptista Villela (1979, p.79): "Sexo é sexo, patrimônio é patrimônio. Se, em geral, já é um princípio de sabedoria e prudência não misturá-los, aqui é definitivamente certo que um nada tem a ver com o outro". A partir desse pensamento, inicia-se a busca pela proteção da igualdade constitucional na premissa de que o Direito é para todos e o Direito de Família tem o objetivo de resguardar a família em sentido amplo como já demostrado.

Mesmo com tanto avanço constitucional, jurídico, legislativo e social, apenas em 2011 o Supremo Tribunal Federal (STF) equiparou as relações homossexuais às uniões estáveis no julgamento da Ação Direta de Inconstitucionalidade (ADI) 4.277 e a Arguição de Descumprimento de Preceito Fundamental (ADPF) 132 (STF, 2011). Procura o judiciário, a partir de então, compreender a igualdade da tutela jurídica concedida aos efeitos das uniões estáveis entre homens e mulheres como avanço digno

\footnotetext{
${ }^{1} \mathrm{O}$ trabalho não se presta as vedações de direitos e deveres em relação as uniões estáveis .
} 
da legislação brasileira e a consagração das consequências dessa relação desencadeando no reconhecimento da família homoafetiva.

E o que as entidades familiares consagradas na união estável e seus efeitos jurídicos têm em comum para que se faça o reconhecimento e equiparação com a família homoafetiva assegurando a Dignidade Humana? A afetividade. O julgamento de 2011 foi todo tratado sob os pilares do principio da afetividade e garantias fundamentais inerentes da Constituição brasileira. Destacando-se a igualdade como direito prevalecente a qualquer"adversidade social". Se o conceito de familia se estendeu abraçando os direitos e deveres das familias constituídas na extramatrimonialidade, também deverá se consagrar nas relações homossexuais ao reconhecer afeto nas famílias homoafetivas.

O teor, resumidamente, das considerações dos ministros, nesse histórico julgamento, pautam-se no reconhecimentodo direito da união contínua, pública e duradoura, como na união estável, afastando o requisito de diversidade sexual e reconhecendo a união entre pessoas do mesmo sexo como "entidade familiar". O argumento central baseia na interpretação do conceito de família em não ser reducionista de direitos por, também reconheceras famílias concebidas alheias às vias do casamento civil. E então que o afeto se fez tão decisivo no questionamento.

O "constituinte espancou séculos de hipocrisia e preconceito" ao normatizar proteção à família sob o aspecto afetivo e atribui a essa instituição a "mola precursora" para a regulamentação das Uniões Homoafetivas, segundo Maria Berenice Dias (2015, a).

\begin{abstract}
A Constituição, ao outorgar proteção à familia, independentemente da celebração do casamento, vincou um novo conceito de entidade familiar, albergando vínculos afetivos outros. Mas é meramente exemplificativo o enunciado constitucional ao fazer referência expressa à união estável entre um homem e uma mulher e às relações de um dos ascendentes com sua prole. O caput do art. $226^{2}$ é, conseqüentemente, cláusula geral de inclusão, não sendo admissível excluir qualquer entidade que preencha os requisitos de afetividade,estabilidade e ostensibilidade.
\end{abstract}

Portanto, o que se extrai dos argumentos utilizados pelos ministros do STF em decisão histórica é, sem dúvidas, o pensamento com base da entidade familiar e seu 
conteúdo afetivo demostrando que o judiciário está a par das lutas sociais, conforme coaduna Nery (NERY JUNIOR, 2013, p.269)

Contudo, pode-se perceber que o judiciário está acompanhando as lutas sociais pela tutela dos direitos e efeitos jurídicos da União Homoafetiva na tentativa de se consolidar os princípios constitucionais. Assim, ao equiparar a união estável a uniãohomoafetiva, em 2011, o STF aplicou a teoria do direito fundamental, principalmente, pautado pelo fundamento da republica da Dignidade da Pessoa Humana por reconhecer, ante a qualquer dilema imposto, a preferencia sexual como direito emanação do principio da dignidade da pessoa humana.

No mesmo sentido Dias (2015 a):

O julgamento unânime do Supremo Tribunal Federal, ao reconhecer as uniões homoafetivas como entidade familiar, ratificou 10 anos de avanços no âmbito do Poder Judiciário, que já havia acumulado mais de mil decisões assegurando um punhado de direitos à população LGBT - lésbicas, gays, bissexuais, travestis e bissexuais. Como a decisão foi proferida em sede de Ação Direta de Inconstitucionalidade, tem caráter vinculante e eficácia contra todos, ninguém - nem a justiça e nem qualquer órgão da administração pública federal, estadual ou municipal - pode negar que as uniões de pessoas do mesmo são uma entidade familiar, sinônimo perfeito de família e merecedoras dos mesmos direitos e deveres da união estável.

$\mathrm{O}$ avanço jurisprudencial sobre o tema união homoafetiva ganha as pautas sociais e garantindo avanços sociais e legais únicos. Nesse sentido, destaca-se o RESP

1183378, de origem do Rio Grande do Sul que em 2011 tratou do assunto casamento homoafetivoque sem qualquer repudio ou vedação de legislação. Também pautou seu julgamento na entidade familiar como "poliformismo familiar (STF, 2011)".

Torna-se, o valor jurídico do afeto premissa para os desdobramentos do judiciário na construção dos novos paradigmas das familias brasileiras e a inclusão da família homoafetiva nessa seara. "A dimensão constitucional do afeto como um dos fundamentos da família moderna - o reconhecimento do afeto como um valor jurídico impregnado de natureza constitucional: um novo paradigma que informa e inspira a formulação do próprio conceito de família (DINIZ, 2015.p.447)".

Ademais, segundo Nery (2013, p.270), o Direito também possui premissa à busca da felicidade, "um salto normativo na proibição do preconceito para a proclamação do direito a liberdade sexual" Por esse prisma, o afeto fez-se de suma 
importância assegurando o direito à autonomia da vontade quanto à sexualidade e sucessivamente o direito subjetivo de constituir família pautado na felicidade dos cidadãos como direito fundamental ao bem-estar social. Destaca-se a jurisprudência brasileira que aplica o princípio da afetividade, com a predominância na concretização de "família", na sua forma mais ampla possível. É o que se segue (NERY, 2013. p, 270).

O que deve balizar o conceito de "família" é, sobretudo, o princípio da afetividade, que "fundamenta o direito de família na estabilidade das relações socioafetivas e na comunhão de vida, com primazia sobre as considerações de caráter patrimonial ou biológico.

A afetividade é o principio norteador do moderno Direito de Família permitindo a evolução jurídica e social cunhado no reconhecimento de família homoafetivae seus direitos e garantias constitucionais a partir da compreensão de família em sentido amplo. A luta pela inclusão da afetividade, consagrada pelo principio constitucional da Dignidade da Pessoa Humana, ventou nas relações homossexuais de que elas também seriam famílias e, portanto, passíveis de direitos e deveres como o casamento e a união estável. Surge, nesse cenário de contemplação da felicidade, a "famîlia homoafetiva" como Justiça!

\section{A EXCLUSÃO DOS IGUAIS: HOMOFOBIA E A MARGINALIZAÇÃO LEGAL DOS DIREITOS HOMOAFETIVOS}

Volta-se a realidade das famílias homoafetivasinseridas na marginalização legal e nitidamente suscetível à vulnerabilidade. Os avanços sociais e jurídicos são muitos e transformam aos poucos a triste condição daqueles julgados "diferentes". É bem verdade que somado a evolução do Poder Judiciário estão as Políticas e Públicas, atuação do terceiro setor, globalização de direitos através de fóruns sociais mundiais, entre tantos outros.

No entanto, a realidade brasileira é dúbia e, ainda, caminha a passos lentos rumo à igualdade jurídica no tocante a diversidade sexual. Nesse sentido, a lacuna legislativa pode resultar em inúmeros percalços travando o desenvolvimento digno da sociedade. As discrepantes decisões jurídicas também demostram tal situação.Buscar direitos, ainda é um entrave burocrático e muitas vezes de difícil acesso, ocasionando a 
"exclusão" dos homossexuais aos direitos constitucionalmente assegurados. A sociedade ao mesmo tempo em que luta pela igualdade de direitos luta contrariamente pela exclusão social das famílias homoafetivas resultando na crescente piora de dados da homofobia.

Evidencia-se um cenário de preconceito e discriminação social e jurídica que, nitidamente, violam a proteção do indivíduo, principalmente das minorias em que são mais vulneráveis. E deve o Direito, e seu caráter organizacional, direcionar a sociedade para afastar a exclusão de direitos. Nesse sentido (DIAS, 2009)

As leis servem de norte de como as pessoas devem agir. Criam pautas de conduta, modelos de comportamentos que irão reger a vida em sociedade. Este é o significado maior da atividade legiferante. Mas o sistema legal precisa contemplar todos os segmentos sociais, não só os que são compostos por um número maior de cidadãos. Como as minorias são mais vulneráveis, precisam da especial proteção do Estado. Sem uma atenção diferenciada tornam-se alvo da rejeição por parte da maioria. Por isso é indispensável a adoção das chamadas ações afirmativas.

Contudo, a falta de legislação ainda proporciona situações de entraves e exclusões, pois, mesmo que a Constituição Federal atribua às famílias brasileiras uma base calcada na afetividadereconhecida por precedente do STF não houve estipulação expressa no texto constitucional no tocante as relações homoafetivase assim, parcela da sociedade repudia e afasta a importância do afeto ao negar a existência de uniões homoafetivas pela ausência do termo no texto constitucional refletindo no judiciário. Maria Berenice Dias (2009) pondera que prevalece na sociedade a primazia da moral e dos bons costumes gerando a exclusão, o preconceito e a discriminação dos homossexuais.

Apesar de todos os dogmas, princípios e regras, que buscam assegurar a primazia dos direitos humanos, a sociedade, em nome da preservação da moral e dos bons costumes, impõe padrões de comportamento restritos. Com seu perfil nitidamente conservador, cultua valores absolutamente estigmatizantes, insistindo em repetir o modelo posto. Tal postura gera um sistema de exclusões baseado muitas vezes em meros preconceitos. Tudo o que se situa fora do estereótipo acaba sendo rotulado de "anormal", ou seja, fora da normalidade. O que não se encaixa nos padrões aceitos pela maioria é apontado como uma afronta à moral e aos bons costumes. Essa visão polarizada é extremamente limitante. 
A triste realidade homofóbica no Brasil é ilustrada pelos jornais cotidianamente conformadas pelas estatísticas de violência o que para muitos estudiosos é ocasionada pela falta de composição legal. Discute-se, para tanto, nesse caso de vulnerabilidade a lei é impositiva para que a sociedade compreenda que respeito à dignidade da pessoa humana deve prevalecer sobre qualquer dilema, principalmente, sobre a moral, com intuito de evitar atrocidades e abusos aos direitos fundamentais dos homossexuais.

Os dados da secretaria de direitos Humanos da Presidência da República,lançado em 2011,confirmam o entendimento acima ao afirmar que a ações homofóbicas são constantes afastando a cidadania e seguridade dos Direitos Humanos. O estudo comprovou que há no Brasil uma situação extremamente delicada sobre a violência contra a diversidade sexual e assim, no ano de 2011, foram reportadas 18,65 violações de direitos humanos de caráter homofóbico por dia. $\mathrm{O}$ que permite concluir que a homofobia no Brasil é estrutural e com esse cenário negativo a construção do Direito Homoafetivo (FARO, PESSANHA, 2015).

O cenário é típico de exclusão social ameaçando a dignidade humana e o bemestar social da coletividade, pois, as relações homoafetivas imperam, mesmo com tamanhas divergências em meio ao cenário homofóbico. Saindo da espera de exclusão social tratado pelo tema homofobia adentra-se aos entraves jurídicos ocasionados por falta de legislação pertinente aos temas. Ainda impera sobre a evolução do Poder Judiciário e afasta das relações homoafetivas muitos direitos e deveres já consagrados às entidades familiares.

\subsection{DIFICULDADES NA TUTELA AO DIREITO RECONHECIDO: A LACUNA LEGISLATIVA}

Primeiramente, pode-se exemplificar as dificuldades de reconhecimento de direitos e deveres na situação de reconhecimento de união estável homoafetiva mesmo com precedente do STF em 2011. Não foi de imediato adesão dos estados em relação ao tema. As diversidades de decisões levaram o conselho Nacional de Justiça (CNJ) a editar no ano de 2013, a Resolução de número 175 com teor de proibir as autoridades competentes se recusassem a habilitar, celebrar casamentos civis ou converter união estável em casamento entre pessoas do mesmo sexo. A situação tomou tamanha proporções que o $\mathrm{CNJ}$, mesmo nãosendo órgão legislativo atuou na proteção dos direitos fundamentais do individuo. 
Verifica, ainda, algumas impossibilidades e ate mesmo vedações quanto o cadastro de casais homoafetivos para adoção. Algumas interpretações dos órgãos administrativos e judiciários acabam por restringir o direito ao casal ao estipular qual seria a melhor opção quanto ao sexo da criança, como se verifica no julgado a seguir. A título de exemplo segue a decisão de primeira instancia no estado de São Paulo sobre o assunto (TJSP, 2012).

\begin{abstract}
São Paulo - Pirassununga - Apelação. Procedimento de habilitação no cadastro de pretendentes à adoção, por casal em união homoafetiva. Deferimento, com ressalva de vedação à adoção de infante masculino. Alegação do Juízo de que a adoção de um garoto por mulheres em união homoafetiva não se mostra adequada, vez que a figura paterna é essencial para a formação de sua personalidade.
\end{abstract}

Em relação ao INSS, o instituto regulou o assunto concessão de beneficio nas relações homoafetivas ao companheiro ou companheira na instrução normativa $\mathrm{n}^{\mathrm{o}} 25$ de de junho de 2000 para atender a determinanação judicial expedida pela juíza Simone Barbasian Fortes, da terceira vara previdenciária de porto alegre, ao deferir medida liminar na ACP 2000.71.00.009347, com eficácia erga omnes para atender ao pedido de beneficio em união Homoafetiva (NERY JUNIOR, 2013).

\title{
CONCLUSÃO
}

O cenário ainda é de desgastes e discrepâncias quanto a busca aos direitos e deveres como consequência de uniões homoafetivas. Nitidamente, a exclusão é um contraditório na evolução do Poder Judiciário em relação aos Novos Paradigmas do moderno Direito de família, evidenciando, ademais, a ameaça a Dignidade da Pessoa Humana resultante das uniões homossexuais.A jurisprudência atual, apesar dos entraves na busca a proteção de direitos e deveres a casais homossexuais e crescentes homofobia, além de equiparar direitos, pauta-se na Dignidade humana e igualdade constitucional para argumentar suas decisões consagrando a afetividade nas familias homoafetivas, conforme decisão do Ministro Celso De Mello no HC 85988 do Pará em 10 de junho

2005 (NERY, 2013)

a dignidade da pessoa humana é principio central do sistema jurídico, sendo significativo vetor interpretativo, verdadeiro valor-fonte que conforma e inspira todo o ordenamento constitucional vigente em nosso país e que traduz, de modo expressivo, um dos fundamentos em 
que se assenta, entre nós, a ordem republicana e democrática consagrada pelo sistema de direito constitucional positivo.

Sob esse enfoque, é nítida a necessidade de proteção aos direitos humanos fundamentais de grupos sociais tendentes a exclusão de direitos e marginalização legal e social como o disposto no trabalho. Cabe, portanto, ao Estado, o "dever de criar as condições para levar isso (dignidade humana) a cabo, de tal sorte que a dignidade humana não seja violada por terceiros (integrantes da sociedade)" (HARBELE, 1997).

O contexto de familia homoafetiva é pautado, ainda,na "Justiça" e "Exclusão" dos direitos fundamentais do ser humano. O direito de Família tutela a consagração da afetividade e o reconhecimento das entidades familiares além do matrimonio em uma situação evidente de "justiça" social, mas, as discrepantes decisões, entraves jurídicos, crescente homofobia e marginalização legal colocam as relações homoafetivas em uma contrariedade que não deve ser permitida pelo Direito.

A dignidade humana deve ser apreciada rigorosamente nas tutelas jurídicas das uniões homoafetivas. Nesse sentido, a afetividade será a consequência prevista na atuação do Poder Judiciário e ações afirmativas do Poder Público perante a lacuna legislativa para concretizar os direitos humanos fundamentais dos homossexuais e evoluir no âmbito jurídico e social como vem se concretizando o direito de família brasileiro. Assim, além do cenário de exclusão e justiça, a familia homoafetiva nasce como nova família brasileira e o Direito deve tutelar o amor e a felicidade aquém da diversidade sexual.

\section{REFERÊNCIAS}

BEVILAQUA, Clovis. Código Civil dos estados unidos do Brasil comentado. 5.ed.São Paulo: Francisco Alves, 1937. p, 6COULANGES, Fustel de. A cidade antiga. 9.ed.Lisboa: Almedina, 1958, p. 69.

DIAS, Maria Berenice. Manual de direito das famílias. São Paulo: Revista dos Tribunais, 2009. . União Homoafetival, o Preconceito e a Justiça. 4. ed. São Paulo: Editora Revista dos Tribunais, 2009.

A democratização do casamento. Disponível em:

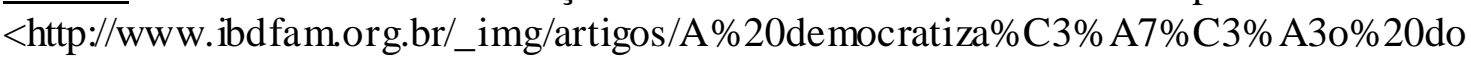
\%20casamento.pdf.> Acesso em: 06 maio 2015.

Um novo direito Homoafetivo. Disponível em:

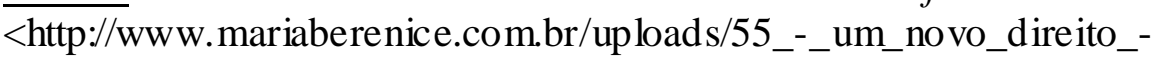
_direito_homoafetivo.pdf> .Acesso em: 25 mar. 2015a. 
União Homossexual: O Preconceito e a Justiça. $5^{\circ}$ ed. São Paulo: Revista dos Tribunais. 2005.

$$
\text { Família homoafetiva e seus direitos. Disponivel em: }
$$

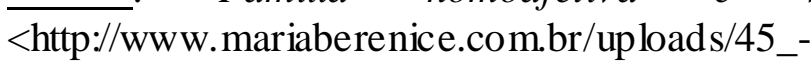

_a_fam\%EDlia_homoafetiva_e_seus_direitos.pdf>. Acesso em: 03 mar. 2015.

. A homoafetividade $e$ a justiça, 2010. Disponível em:

$\langle\mathrm{http}: / /$ www.mariaberenice.com.br/uploads/33_-

_a_homoafetividade_e_a_justi\%E7a.pdf, 01-06-2012>. Acesso em : 12 abr. 2015b.

DINIZ, Maria Helena. Teoria Geral do Direito Civil . Sao Paulo: Saraiva 32a Ed. 2015, p 447

FARO, Julio Pinheiro; PESSANHA, Jackeline Fraga. O casamento civil homoafetivo e sua regulamentação no Brasil. Disponível em: $<$ http://www.direitohomoafetivo.com.br/anexos/artigo/121_feaf705d0e755bbf2e1fb11

3aba748d4.pdf >. acesso em: 25 abr. 2015.

FERREIRA FILHO, Manoel Gonçalves. Direitos humanos fundamentais. São Paulo: Saraiva, 1995.

GOLIN, Célio; POCALY, Fernando Altair; RIOS, Roger Raupp (Orgs.). A Justiça e os direitos de gays e lésbicas: jurisprudência comentada. Porto Alegre: Editora Sulina, 2003.

COULANGES, Fustel de. A cidade antiga. 9.ed.Lisboa: Almedina, 1958, p. 69.

GRECO, Rogério. Curso de Direito Penal: parte geral. $2^{\mathrm{a}}$ ed., rev., ampl. e atual. Rio de Janeiro: Impetus. 2002.

HARBELE, Peter. Hermeneutica constitucional. Porto Alegre: Sergio Antonio Fabris, 1997.

MELlO, Marco Aurélio. A igualdade é colorida. Folha de S. Paulo, São Paulo, 19 ago. 2007.

MORAES, Alexandre. Direitos humanos fundamentais: teoria geral, comentários do art. $1^{o}$ ao $5^{\circ}$ da Constituição da Republica Federativa do Brasil. Doutrina e jurisprudência. 9 ed. São Paulo: Atlas, 2011.

MOTT, Luis. Homo-afetividade e direitos humanos. Homofobia: a violação dos direitos humanos dos gays, lésbicas e travestis no Brasil. San Francisco, USA: Editora IGLRHC, 1997. Disponível em:< http://www.scielo.br/pdf/ref/v14n2/a11v14n2.pdf > . Acesso em: 30 mar. 2015.

. Homossexualidade: mitos e verdades. Salvador: Editora GGB, 2003.

. A revolução homossexual: o poder de um mito. Revista da USP, n. 49 (Dossiê

Política \& Participação), 2001.

NERY JUNIOR, Nelson. Constituição Federal comentada e legislação constitucional. 4.ed.rev.atual e ampl. São Paulo: Revista dos Tribunais. 2013. 
SARMENTO, Daniel. STF manifesta a favor da união homoafetiva. Disponível: $<$ http://www.conjur.com.br/2011- mar-26/grande-chance-stf- manifestar-favor-uniaohomoafetiva>. Acesso em: 25 abr. 2015.

VILLELA. João Baptista. Desbiologização da Paternidade. Revista da Faculdade de Direito da Universidade Federal de Minas Gerais, Belo Horizonte, nº 21, 1979.

VENOSA, Silviio de Salvo, Direito Civil: Direito de Família. 14 e.d. São Paulo: Atlas, 2014, p.01

TARTUCE, Flávio; SIMÃO, José Fernando. Direito Civil. Vol. 6. Direito das Sucessões.

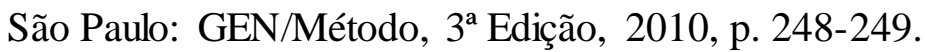

